\title{
Article
}

\section{A theoretical framework for identifying appropriate marketing approaches across the product development life cycle for biomedical science SMEs}

Vahadane, Shashwati Sanjay and Clarke, Andy

Available at http://clok.uclan.ac.uk/40477/

Vahadane, Shashwati Sanjay and Clarke, Andy ORCID: 0000-0003-4291-9851 (2021) A theoretical framework for identifying appropriate marketing approaches across the product development life cycle for biomedical science SMEs. Journal of Small Business and Enterprise Development . ISSN 14626004

It is advisable to refer to the publisher's version if you intend to cite from the work. http://dx.doi.org/10.1108/JSBED-01-2021-0031

For more information about UCLan's research in this area go to http://www.uclan.ac.uk/researchgroups/ and search for <name of research Group>.

For information about Research generally at UCLan please go to http://www.uclan.ac.uk/research/

All outputs in CLoK are protected by Intellectual Property Rights law, including Copyright law. Copyright, IPR and Moral Rights for the works on this site are retained by the individual authors and/or other copyright owners. Terms and conditions for use of this material are defined in the policies page. 


\title{
A theoretical framework for identifying appropriate marketing approaches across the product development life cycle for biomedical science SMEs
}

\author{
Abstract \\ Purpose: An investigation of the marketing approaches for biomedical science SMEs and \\ organisations in the UK was carried out; the research question is: Should the marketing approaches \\ for biomedical science SMEs change as their product or service moves along the development life \\ cycle?
}

Design/methodology/approach: An online questionnaire was used which petitioned biomedical science SMEs and organisations in the UK to investigate the marketing tactics or approaches used for the different products and services they offered; the results were analysed by comparing the results to recognised marketing approaches in the literature, and by mapping those approaches against the established Technology Readiness Levels (TRL).

Findings: A direct relationship was seen between the status of a product or service in relation to its development life cycle, and therefore the relevant TRL of the product and service, and the appropriate marketing approach for that product or service.

Originality: This paper offers a contribution to literature, in that it a theoretical framework is proposed for determining the appropriate marketing approach for biomedical science SMEs by understanding the maturity of the products offered by a company using the established TRL. The theoretical framework maps the TRL against known marketing approaches; this framework should be used as a guide for biomedical science SMEs as a tool to refine and evolve their overall marketing approach as the product portfolio matures along the TRL.

Key Words: Technology Readiness Level; TRL; marketing, Biomedical science SME; product development life cycle

Paper Type: Research paper

\section{Introduction}


Biotechnology plays a vital role in improving health care, industry standards, services, and developing new products within businesses from agriculture to environmental science (Lokko et al. 2018). There is a paucity of research published relating to the level of business acumen within the focused area of biomedical science small to medium sized enterprises (SMEs) in the United Kingdom (UK). Indeed, the biomedical science industry constitutes a developing business market, yet innovative and complex implicit knowledge of this market is understood by very few stakeholders (Wang and Hsu, 2018).

The current research describes a study of biomedical science SMEs and organisations with the aim of the research to explore the implications of various marketing approaches in a biomedical science SME which is looking to grow. The research question is: Should the marketing approaches for biomedical science SMEs change as their product or service moves along the development life cycle? This paper investigates current marketing techniques used by biomedical science SMEs in the UK, and maps those against the position of the product that those SMEs is at on the Technology Readiness Level. A theoretical framework is offered showing the theoretical dependant, independent and mediator variables; this theoretical framework is then refined using the study data. By discussing the results against the literature this paper introduces a conceptual framework for determining the appropriate marketing approach for biomedical science SMEs by understanding the maturity of the products offered by the company in terms of their position in the development life cycle using the established Technology Readiness Level (TRL). The framework maps the TRL against known marketing approaches and should be used as a guide for biomedical science SMEs as a tool to refine and evolve their overall marketing approach as the product portfolio matures.

This paper notes the application of the Bioenterprise Innovation Expertise Model (Gunn 2016) which describes the expertise required for biotechnology innovation; however the proposed framework contributes to the current body of knowledge by empowering the framework user to select the most appropriate marketing approach within biomedical science as the company product portfolio matures (Wang and Hsu, 2018).

\section{Background}

The study examines marketing strategies for biomedical science SMEs and the development of those strategies relative to the service that SME provides. Recent studies suggest that there is an absence of marketing skills in biomedical science companies that might affect the commercial development of that company. These shortfalls have been identified as a problem for young and small biomedical 
science organisations as staff are not exposed to market knowledge (Renko, 2006). These business skills gaps result in biomedical science companies finding difficulties with marketing strategies and building their marketing and sales operations. Which means that biomedical science companies can lack a clear market-oriented focus, along with skills and commercial approaches to direct their organisation as a business towards the markets. It has been stated that many biomedical science university spin offs have no business plans and the cooperation activities are poor (Costa et al., 2004, Rajamäki, 2008, Eriksson and Rajamäki, 2010). Hence, to develop a product portfolio, an understanding of how significant events can influence the route of company's development is required (Pollock et al., 2015).

\section{Literature Review}

Marketing approaches in biomedical science companies

As stated in the literature, many biomedical science companies have no business plans or have poor business planning approaches. The literature continues to note that directors of biomedical sciencebased companies that are research focused may experience difficulties in creating marketing plans. (Costa et al., 2004, Rajamäki, 2008, Eriksson and Rajamäki, 2010). However, there is a strong demand for bioentrepreneurs with materials, sales and marketing skills along with skills involving securing capital and strategic alliances with partners for their respective company (Eriksson and Rajamäki, 2010). Hence, these companies need strong market strategies, and it is vital to explore new approaches towards marketing their services by studying challenges they face in business (Costa et al., 2004).

Biomedical science sector leaders and Directors face difficulties primarily in marketing abilities, and the main problem they face is in how to define the scope of their business (Costa et al., 2004). The literature demonstrates negligence in strategic marketing within areas such as market research, identifying competitors, specific customer needs, product differentiation and positioning (Eriksson and Rajamäki, 2010). Eriksson and Rajamäki, (2010) additionally state that some biomedical science companies display limited marketing and management skills, and later struggle to obtain missing skills and develop new competencies. A distinction is noted in the literature between marketing strategy and marketing tactics or approaches when viewing new product development: marketing strategy decisions focus on the overall tone and direction; marketing tactic or approach concentrate on areas such as communication and promotion, pricing, distribution and implementation (Varadarajan, 2010). Haug et al. (2020) note the role of technological orientation on the adoption of IT processes; this study focused on manufacturing SMEs with highly technical products. The paper notes technology orientation as the ability an inclination to use technology and technical knowledge 
in product development. Haug et al. (2020) posits that as a biomedical science SME would have a high technical orientation, using IT will be more beneficial to the SME and be less affected by the complexity of that IT. Supporting this, Aliasghar et al. (2020) noted no significant relationship between firm performance and innovation in low tech auto companies. The context in which the firm operates is paramount to the expected success of technology adoption. Saura et al. (2021) note the role of data science in digital marketing; data science allows organisations to better understand marketing techniques and therefore which strategies to adopt. Saura et al. (2021) evaluate the influence of data science techniques on digital marketing strategies, noting data science enhances techniques such as social media and social networking, which positively impacts on performance outcomes.

The literature notes basic market approaches which can focus on overall customer needs and strengths of the company, such as the Outside-In and Inside-Out marketing approaches (Frau et al. 2020). With an Outside-In tactic, firms exploit external factors and adjust internal resources; this approach takes external stakeholder satisfaction as its primary issue, hence companies using this approach are focused on customer satisfaction and delivering quality service. Whereas Inside-Out marketing focuses on the company's own capabilities and strengths. This tactic helps the company to focus on resources and providing them effectively; the main limitation to the approach is that it shows slow progress in the marketplace (Frau et al. 2020). However, a study by Mu et al., (2018) stated that Outside-In marketing also provides a more accurate representation of a firm's performance results and it improves the efficacy of marketing capability logic with respect to that firm's performance.

Mu et al., (2018) also stated that an organisation with a strong Outside-In capability can be ineffective in absence of transformational leadership. Transformational leaders are those that create an environment for positive changes to make customer value creation more efficient and effective. Hence when adopting this strategy, it is important to create transformational leadership as an initiative to develop the company. In addition, it is noted to be important for employees to be proactive in their work to maximise the benefit of an Outside-In marketing strategy (Mu et al., 2018). A study by Kremer et al. (2019) noted that research companies also focus on knowledge sharing (KS). $\mathrm{KS}$ is a method where team members share their knowledge between people, teams and institutions; this can include knowledge capture, team briefings, publishing in academic conferences and journals et cetera (Kremer et al., 2019, Liu and Zeinaly, 2020). This method is essential for organisations where they can improve their efficiency and reduce training needs. KS provides creativity and innovation which improves culture and character within the firm (Kremer et al., 2019). 
It is also noted that the managers should create an improved knowledge bank to increase and encourage KS among employees, thus creating and enhancing innovation in organizations (Liu and Zeinaly, 2020). KS is a key success factor that leads to creativity and innovation, in which employees get the most out of the accumulated knowledge in an organisation. Gathered knowledge contributes to the creativity and innovation and involves organisational culture, identity, policies, routines, systems and employees (Kremer et al., 2019). Hence, KS increases creativity and innovation and includes institutional culture and character within the firm which can be helpful for the company's market development.

Howard and Doyle (2006) state that creativity and innovation are not resource intensive in terms of employees and time, and can be improved by simply changing the mindset and adjusting the focus to a specialised approach rather than keeping a generalised approach. In qualitative research, the combination of the insider and outsider views is a productive method for the identification of conceptual and practical diversity of biomedical science marketing. In this way, these concepts could be used to both improve and challenge theoretical discussions about said marketing (Eriksson and Rajamäki, 2010).

\section{Investment and funding issues in biomedical science companies}

The biomedical science industry in the UK, European Union (EU) and United States (US) has undergone significant change in recent years; the dated framework where large companies dominated the production cycle has moved to a framework where large companies focus on later stage development and smaller, focused organisations concentrate on discovery and early-stage development (Gleadle et al. 2012). The biomedical science industry is at the centre of the knowledge economy, and universities are noted to be strong anchor tenants, contributing to the development of knowledge ecosystems (Bains et al. 2014, Fuster et al. 2018, Etzkowitz and Leydesdorff, 2000, Padilla-Meléndez et al. 2000). This relationship and its level of research and innovation means biomedical science spin offs form a useful industry sector to analyse when investigating the relationship between public funding of R\&D activities, knowledge development and firm creation (Kolympiris et al., 2014, Fuster et al. 2018). Funding is noted as one of the biggest challenges for life sciences companies as a vehicle for growth (Oakley, 2003). Government grants are a significant source of funding for researchers looking to develop technologies and as such these can be highly competitive. Depending on the agency or organisation offering the grants, grants have widely varying eligibility, submission, and audit requirements, as well as awards (Kolympiris et al., 2014). Furthermore, government funding can be short term in nature, with no guarantee of on-going support (Oakley, 2003). Yet private equity funding usually requires a display of commercial potential, 
thereby indicating that as a product matures, the source of funding may evolve. Boni in 2018 discusses the use of 'stage appropriate' financing vehicles to support each stage in the maturity cycle of a product: government, private equity and public funding (Boni, 2018).

\section{Privacy and confidentiality issues in biomedical science companies and solutions}

Polvinen et al. (2012) noted that a level of customer understanding and relationships between service providers and customers is crucial when developing a business-to-business commercial context. A study by Schlee and Duzer (2007) investigated the dealing with client information in live case projects and noted issues regarding handling of proprietary or confidential information provided by clients such as market share, customer analysis, customer names et cetera. Willerton (2005) noted that the primary audience for white papers and case studies is prospective customers. Ranchhod et al. (2000) stated that confidentiality of information is a key concern when marketing online. It is widely acknowledged that failure to protect confidential information can result in a reduction in client trust and confidence, leading to the loss of business or clients (Chalmers and Nicol, 2004). Pronk et al. (2015) noted that industries such as biomedical science sector companies may have to deal with issues of confidentiality in forms such as consultancy, contract research and intellectual property (IP) discussions. Pronk et al. (2015) continued to state that employees within this sector need to be fully cognisant of confidentiality issues relating to clients as well as industry and academic partners and stakeholders.

\section{White papers, case-studies and knowledge sharing in marketing}

Demonstrating the benefits of a product or service is a critical element to achieve success in marketing, and the mechanisms used to market a product will be highly different depending on the product. For example, if a customer does not understand the potential benefits of a service or product then it might get difficult for the person to commit to the purchase (Lee and O'Connor 2003). Thompson et al. (2013) note that SMEs using websites as a marketing tactic allows the SME to gain access to customers and suppliers; however, those SMEs are more likely to be innovative but less likely to achieve growth. In a paper in 2010, Eriksson and Rajamäki (2010) investigated the marketing techniques from 5 different biomedical science companies noting the maturity of the product offer from each company. The study demonstrated a different marketing tactic was noted to align to a different level of product maturity. Marketing approaches including conference presentations, case studies and white papers, using the company website, publishing news bulletins and press interviews were employed. 
This current study views case studies and white papers as documents which describe a new or improved technology in order to generate interest in, and promote sales of, that technology (Malone and Wright, 2018). Therefore, use of a study or white paper as a form of science communication in marketing can be a demonstration that indicates the interaction between the end user and a product or service (Weitze and Pühler, 2013). In a doctoral thesis in 2005, Willerton (2005) stated that white papers generally function as marketing documents that mix objective and promotional material, noting that readers of white papers expect technical details, but also acknowledge the white paper serves to promote the sponsoring companies' interests (Willerton 2005). Willerton (2005) continued that the primary purpose of a white paper is lead generation and subsequent sales, with a secondary purpose to educate and inform about a technology or product. Weitze and Pühler (2013) contend that most receivers of science communications are lay persons, therefore will rely on the knowledge of, and trust of experts. A study or white paper may be used to market a technological product or service to other businesses or direct to consumers (Malone and Wright, 2018).

Kremer et al., (2019) state that firms that connect the creativity of their workforces to transform ideas into new products and services pull ahead of the competition. The research provided considerable experiential evidence concerning the critical role of knowledge sharing (KS) as success factors for creativity and innovation (Kremer et al., 2019). Ipe (2003) note that an organisations ability to leverage its knowledge is highly dependent on its people, who create, share and use the knowledge. KS has a positive effect on innovation as it increases the marketing capability of biomedical science firms to a higher level to achieve their target aims, learning new techniques, protecting valuable research, creating core capabilities, initiating new situations and creating productivity providing competitive merit for an institution (Liu and Zeinaly, 2020).

The findings of Wang and Wang (2012) support the literature by stating that KS has a positive relationship with innovation, which can contribute to a firm's performance. Considering this it is possible that white paper and case studies based on knowledge sharing can help improve brand awareness as well as productivity within the organisation (Wang and Wang, 2012). In the biomedical science sector it may not always be possible to share knowledge as it may breach the confidentiality agreements however, keeping specific details aside it can be possible to share new ideas and experience with the help of white papers and case studies. Fernie et al. (2003) proposed a method for KS looking at a chosen subject or topic, defining background research, understanding explicit and tacit knowledge, and embedding those findings into a report. As such, for the purposes of this paper, KS can take the form of white papers, case studies, conference papers, peer review journal papers et cetera. 


\section{Technology Readiness Level}

In the mid 1970s the National Aeronautics and Space Administration (NASA) introduced Technology Readiness Levels (TRL) to allow more effective valuation and communication concerning the maturity and growth of new technologies (Mankins, 2009). TRL is sector and discipline independent and can be applied to all projects and research fields; noted to be highly effective in communicating the maturity of new technologies (Mankins, 2009). When using the TRL, technology readiness assessments (TRA) are carried out, ideally at several points in the development life cycle of a new technology (Mankins, 2009). In 2018, Lane (2018) noted that in the bioeconomy, TRLs 1-3 may represent fundamental R\&D, TRLs 4-6 scale-up and integration, and TRLs 7-9 demonstration and commercial deployment. Lane (2018) continued to note that progression from one level to the next requires funding: postulating that TRLs 1-2 are typically achieved with government or academic grants, TRLs 3-4 with seed rounds, and TRLs 5-7 with funding rounds. Reaching the final TRLs 8 and 9 (building large plants) generally requires a bank loan for capital equipment and construction (Lane, 2018).

\section{Methodology}

Research Methods

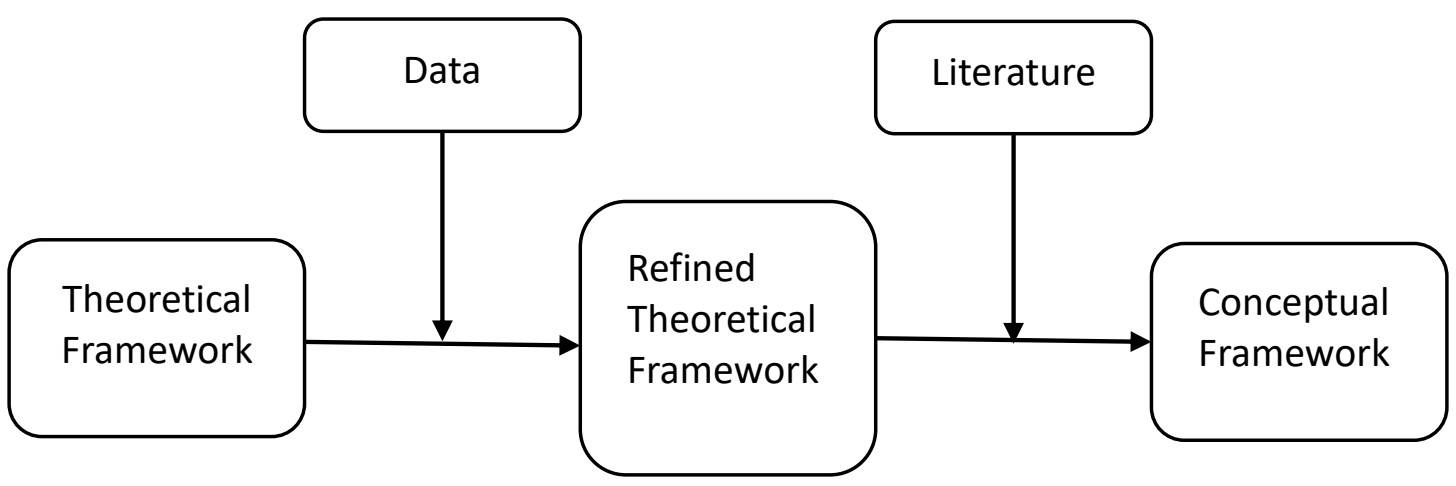

Figure 1. Research Methods Diagram (source: developed by author for the study) The research method (Figure 1) offered a theoretical framework, which was then refined using the data collected. This was then validated against the literature and a conceptual framework is offered.

\section{Research framework}

This study proposes a research theoretical framework (Figure 2). The research framework shows that intellectual capital is directly related to the marketing approach, however a deeper understanding of the interrelation between intellectual capital (including organisational, 
entrepreneurial, and human capital), and the position of the product on the technology readiness level in terms of product changes, can offer a more specific approach to marketing a product.

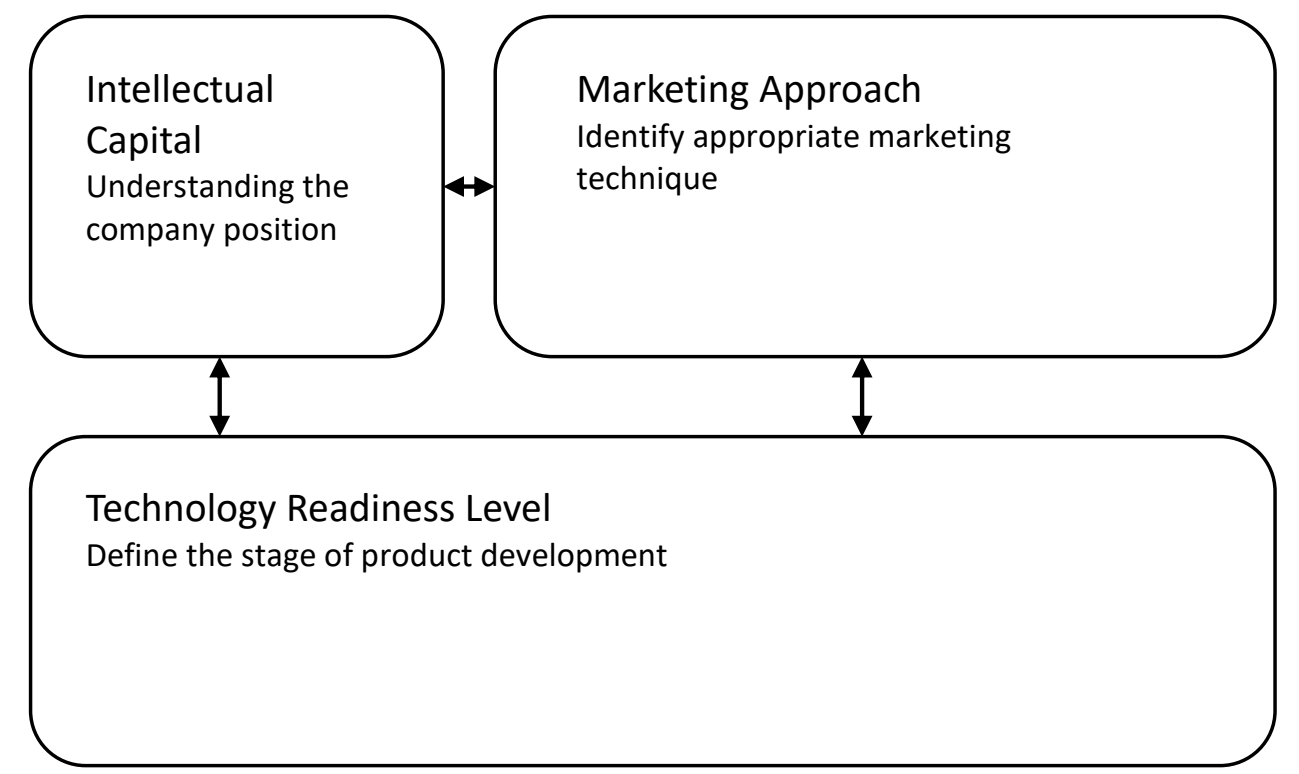

Figure 2. Research Theoretical Framework (source: developed by author for the study)

The research framework uses a cause-and-effect relationship between the intellectual capital of an SME and the marketing approach that SME uses; intellectual capital is the independent variable and marketing approach is the dependent variable. The TRL is the mediator variable in this framework as the TRL is affected by the intellectual capital.

A questionnaire was circulated to a population size was $n=10.19$ questions were organised into 6 themes and emailed to a total of 10 randomly selected biomedical science companies and participants.

\section{Company Structure}

1. When did your company receive its first funding?

2. Which sources of funding have you used?

3. Which territories is your company active in?

4. Do you have to work with healthcare suppliers?

5. Is the need of Investment the biggest challenge your company is facing?

6. Has the UK government's Free Trade Marketing Agreement provided your company new opportunities? 
7. How often does a negotiation between the buyer and the client go in your company's favour?

8. How progressed do you think is your company's research?

University Support

9. How much support does your company get from universities?

Technology Readiness Level

10. What is the TRL of your services?

Company Strategies

11. What are the biggest strengths, weaknesses and threats you see in your company?

12. What marketing sources has your company used in the past?

13. How likely is it your competitors produce challenges for your company?

14. How challenging do you think it is to market multiple services together in your company? Confidentiality

15. Has your company faced any situations over confidentiality with clients?

16. How challenging do you think it is maintaining confidentiality when marketing a service/solution for your company?

Company Challenges

17. What kind of change or addition would you suggest towards the overall development of your company?

18. In general, how challenging do you think is it to pursue the UK Government to grant funding over high-tech research?

19. In your opinion, how easy is it to access UK Government funding?

Validity and reliability

As this study is focused on marketing in scientific terms, the outsider view research approach is used (Douglas and Craig, 2006). Using the outsider approach, theory and concepts are universal and are applicable across countries, industries and companies (Douglas and Craig, 2006). Hence, the research lies in questions such as, what does marketing mean for researchers in biomedical science companies? However, the theories in this approach are not expressed in the similar way in different social and cultural contexts and hence, an insider view is required in the study (Douglas and Craig, 2006).

The insider approach works well with the people involved in marketing within a certain sociocultural context, such as the biomedical science sector (Cook, 2006). Studying biomedical science marketing with an insider view, the research is based on questions like, how do the researchers 
explain what marketing means for biotechnology companies? Many studies suggested that it is effective to combine the insider and the outsider views together (Cook, 2006). Hence, this study starts with an insider view concentrating on how scientist-managers of biomedical science companies define what marketing means in their own company. Then, it further continues by adding the outsider view to the research.

Data collection was conducted via email questionnaire; the questionnaire used a combination of open-end questions and questions which asked for a response using a 5-point Likert scale:

(1) Strongly disagree; (2) Disagree; (3) Neither agree nor disagree; (4) Agree; (5) Strongly agree (Saunders et al., 2019). 10 participants / companies were randomly selected to take part in this study. Selection of participants / companies was based on previously known company data and therefore did not impose bias into the results.

The questionnaire contained questions specifically about the organisation, such as growth and funding year, reasons of certain actions for example; the questionnaire also requested respondents to focus on the overall biomedical science sector; hence the biomedical science employees needed to complete both the sections, whereas those who are not employed in a biomedical science SME were asked to complete only the second section. This method provided an overall transparency of the results by keeping relevant questions to each candidate (Rampersad et al., 2010). The data collection can be described as deductive because the study began with a theoretical framework (Figure 2 refers) (Saunders et al., 2019). However, there was no scope of additional new follow-up questions as the questionnaire was emailed based (Lindstrand et al., 2011). Descriptive statistical analysis was used to focus on the central tendency that represents the value that occurs most frequently to gain a greater understanding of how intellectual capital relates to product development and marketing approach (Saunders et al., 2019).

\section{Limitations of the Study}

The study is limited by the population size of 10 . A larger population size would allow a more robust validation of the research framework. In addition, there is a paucity of research in this area to build upon, however this study does therefore identify a gap in the body of knowledge.

\section{Results}

Results are presented within the question themes: 
Company Structure: From the population size of 10, 6 responses noted the year the company first received funding in the range 2009 (10\%), 2012 (10\%), 2016 (10\%), $2018(20 \%)$ and 2019 (10\%) and funding identified to include angel investors, government and private funding. When asked which countries companies have a presence in, responses indicated a global reach including UK (40\%), North America (40\%), EU (30\%), West Africa (20\%), India (10\%), East Asia (10\%). From all responses $(n=8) 50 \%$ of responses (4) indicated that they did work with another healthcare supplier with the remaining 50\% doing so. On assessing negotiation between buyers and clients, and if this went in the company's favour $-36 \%$ of respondents felt that it is highly likely for negotiations to go in their favour, with $29 \%$ likely, $21 \%$ neither likely or not likely, and $14 \%$ somewhat unlikely. When asked how progressed the company's research is, $43 \%$ of respondents replied neither progressed or not progressed, and $57 \%$ progressed.

University Support: Respondents indicated support from less support (7\%), some support (13\%), neither supported or not supported (20\%), good support (27\%) to very good support (33\%), with $60 \%$ indicating very good or good support. This aligns with Fuster et al., (2018) where university spin off companies should aim to receive as high a degree of support as possible from the partner university.

Technology Readiness Level: when asked what TRL products were at, 7 respondents noted products in the TRL of $2(28 \%), 3(48 \%), 4(57 \%), 5(14 \%), 7$ (28\%), 9 (14\%). A visual representation of the TRL data is shown below (Figure 3 ).

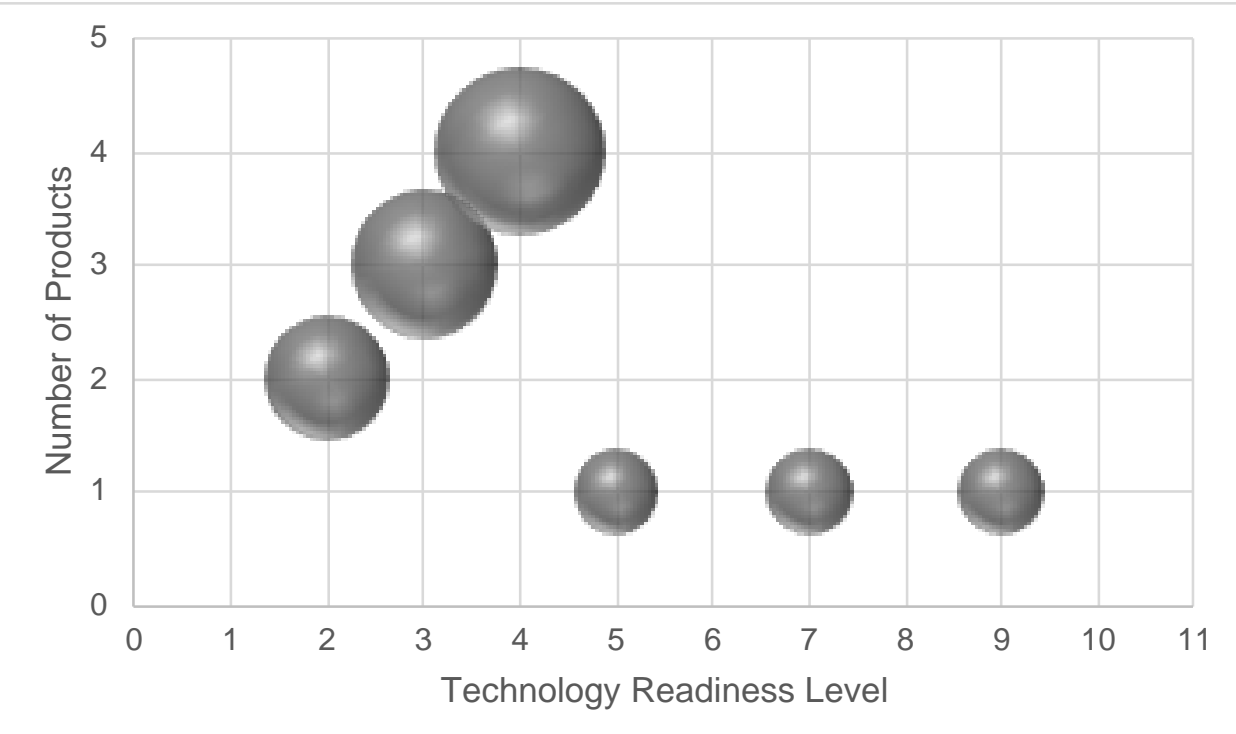

Figure 3. Illustration range of products by TRL 
Company Strategies: When asked about the strengths, weaknesses and threats the company's face, the following was noted $(n=8)$ :

Strengths: innovation (37\%), strong academic foundation, IP portfolio, disruptive technology, breadth of expertise, and technology all returned the same value $(12 \%)$

Threats: competitors, investment and commercialisation (25\%), relative size, financial support, sales and lack of resource (12\%).

Weaknesses: companies taking IP (25\%), university policy, lack of money and resources, loss of staff, time to market (12\%).

Respondents noted marketing approaches used to be social media (37\%), publications and general websites (25\%), staff web pages and lack of time (12\%). Respondents noted the likelihood of challenges from competitors $(n=10)$ to be with $30 \%$ very likely, $50 \%$ somewhat likely, and $20 \%$ neither likely or not likely. When asked how challenging it is to market multiple services together from one company $(n=10)$, respondents noted extremely challenging $(20 \%)$, somewhat challenging $(40 \%)$, neither challenging or not challenging $(30 \%)$, less challenging $(10 \%)$. Companies can create ideas to improve market strategies over these strengths and that can help design the strategy accordingly, however a low level of marketing insight was noted due to the main marketing strategies being social media and publications. This concurs with Costa et al., (2004), Rajamäki (2008), Eriksson and Rajamäki (2010) and Thompson et al., (2013).

Confidentiality: when asked if respondents have faced any situations over confidentiality with clients $(n=10), 60 \%$ responded no and $40 \%$ responded yes. When asked how challenging it is maintaining confidentiality when marketing a service/solution $(n=10)$, respondents replied $20 \%$ very likely, $20 \%$ somewhat likely, and $40 \%$ neither likely or not likely, and $20 \%$ somewhat unlikely. This indicates confidentiality is a challenge in the field of marketing, aligning to (Ranchhod et al., 2000, Chalmers and Nichol, 2004, Pronk et al., 2015).

Company Challenges: When asked what kind of change or addition would be suggested towards the overall development, respondents $(n=8)$ replied new talent and more funding $(20 \%)$, and partnering, deeper capability, and achieving recurring users (10\%). The question of how challenging it is to pursue UK Government grant funding for hi-tech research, respondents $(n=10)$ replied extremely challenging $(60 \%)$, somewhat challenging $(20 \%)$, neither challenging or not challenging $(20 \%)$. Respondents $(n=9)$ replied to the question of how easy it is to access UK Government funding, with 
it's a political decision and the company is in the middle TRL so high risk (20\%), and highly competitive, funding lands in the 'golden triangle', there is a low success rate, and technical writing is required (10\%). The respondents also replied that government agencies find it difficult to interact with SME's (small to medium size enterprises). Also, that the UK Government funding bodies do not want to be involved with just one company, and funding decisions can be political ones and not scientific ones. This concurs with Oakley (2003) and Kolympiris et al. (2014).

By refining and training the theoretical framework using the results from the questionnaire, the following can be seen:

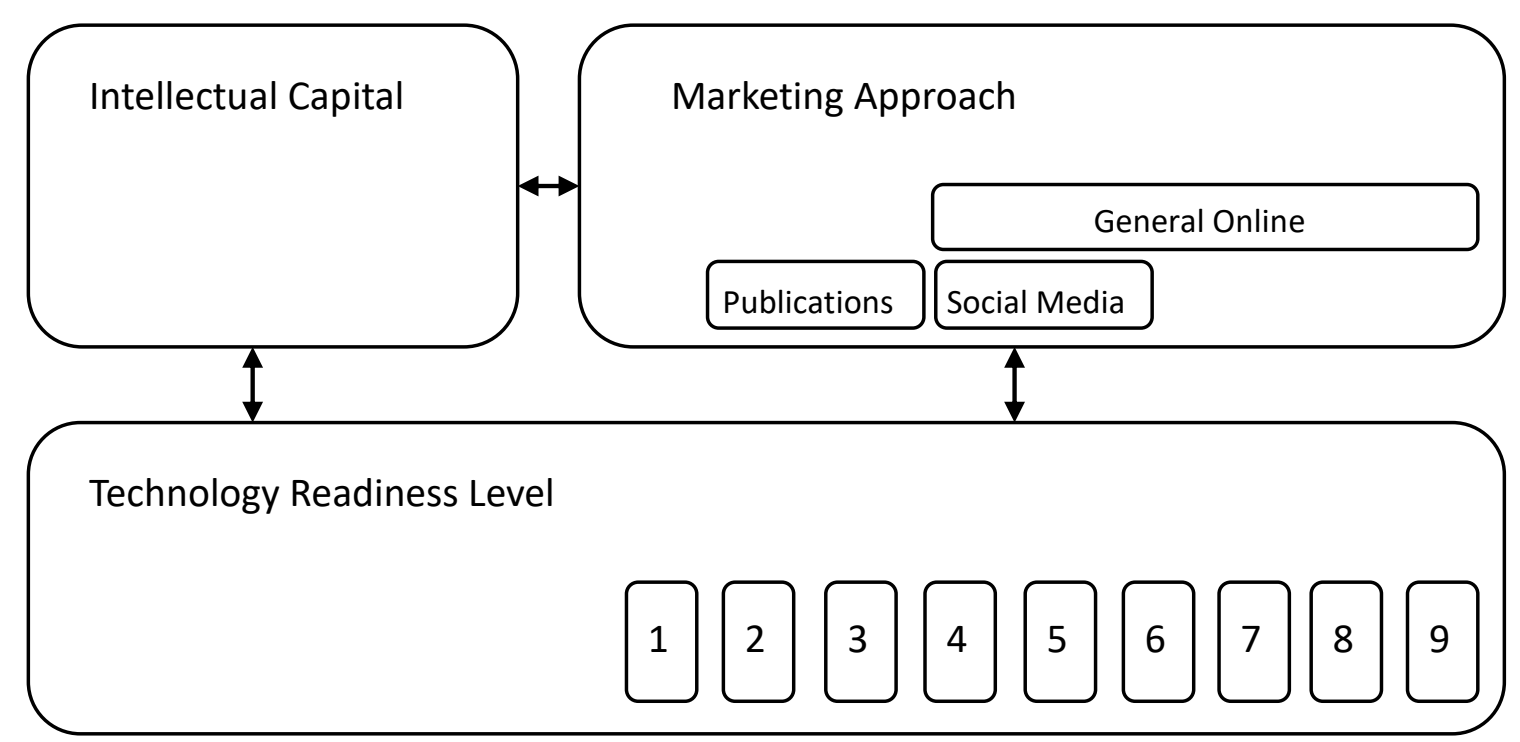

Figure 4. Refined Theoretical Framework (source: developed by author for the study)

The refined framework (Figure 4) includes the data from the marketing approaches noted mapped against the TRL. This shows how the marketing approach used varies according to the TRL of the product offer.

\section{Discussion}

\section{Funding}

The results broadly align with the literature; Boni (2018) noted that 'stage appropriate funding' is required. The results show a range of funding sources, and a wide range of TRLs reported across the service spectrum, aligning to Lane (2018). $60 \%$ of respondents noted funding to be the biggest challenge the company is facing and more funding appeared most frequently when asked about development needs for the company, concurring with Oakley (2003), Renko (2014) and Kolympiris et 
al. (2014). 75\% of respondents also noted that achieving successful government grants are challenging or extremely challenging, aligning with Oakley (2003) and Kolympiris et al., (2014). Respondents noted that having services which sit in the middle TRL band creates a funding issue, and that funding is a political decision and highly competitive. As per the responses received, the reasons for these difficulties are a lack of connections with political circles and government do not wish to be seen to support any one technology or one company. This means that the company will need external support and networks which are currently outside their reach. By forming an approach of a deeper advocacy from the partner university, that advocacy can be leveraged to increase the success rate of funding applications.

\section{Marketing Tactics}

The literature noted a strong demand for bioentrepreneurs with materials, sales and marketing skills along with skills involving securing capital and strategic alliances with partners for their respective company (Eriksson and Rajamäki, 2010). 36\% of respondents felt that it is highly likely for negotiations to go in their favour, with $29 \%$ likely, $21 \%$ neither likely or not likely, and $14 \%$ somewhat unlikely; these results indicate a mixed approach to negotiation. Respondents indicated $42 \%$ noted competitors are more likely to create challenges, with $33 \%$ likely and $25 \%$ neither more or less likely, and $67 \%$ of respondents noted marketing multiple services is challenging or extremely challenging. Respondents also stated other companies taking IP, and competitors and lack of commercialisation to be the biggest Threats and Weaknesses, with publications and social media being the main marketing approaches. This concurs with Costa et al. (2004), Rajamäki (2008) and Eriksson and Rajamäki (2010), where difficulties in defining the scope of the business, and in limited marketing and management skills are noted.

\section{University Support}

Biomedical science SMEs traditionally maintain good relationships with universities, enabling the SMEs to get rapid access to results data (Festel et al. 2012). When asked about the level of university support, respondents indicated a range of support from less support to very good support, with $60 \%$ indicating very good or good support. This aligns with Fuster et al. (2018) where university spin off companies should aim to receive as high a degree of support as possible from the partner university. However, this support is not being realised in funding bid success. Respondents note a lack of political networks that may help them to realise an increase in government funding. Buganza et al. (2014) noted that the relationship between an SME and a university changes as the product maturity develops, stating that trust and confidence between the two parties grows as the collaborative 
relationship develops. Aligning with Oakley (2003) and Kolympiris et al. (2014), if over time the company leverages more marketing and networking support from the university this will enhance the funding bid success rate; hence, by improving the support from the partner university, the company will contribute more to the knowledge economy, aligning with Etzkowitz and Leydesdorff (2000), Padilla-Meléndez et al. (2020).

\section{Knowledge Sharing}

Knowledge Sharing (KS) is a method where team members share their knowledge between people, teams and institutions; this can include knowledge capture, team briefings, publishing in academic conferences and journals et cetera (Kremer et al., 2019, Liu and Zeinaly, 2020). This method is essential for organisations where they can improve their efficiency and reduce training needs. KS provides creativity and innovation which improves culture and character within the firm (Kremer et al., 2019).

The findings of Wang and Wang (2012) also show that KS has a positive relationship with innovation, which can contribute to a firm's performance. The results show that the use of social media and publications in the main, and therefore partially engage in KS. As noted in the literature, directors of biomedical science and science-based companies that are research focused may experience difficulties in creating marketing plans. (Costa et al., 2004, Rajamäki, 2008, Eriksson and Rajamäki, 2010). Eriksson and Rajamäki (2010) showed that a different marketing tactic was noted to align to a different level of product maturity. The results of this study show that the marketing approches of the biomedical science companies do not align to the literature in that one approach is used across multiple services and TRLs, however the results show the companies do align to the literature in that the Directors of the companies may experience difficulties in writing marketing plans. By establishing a culture of KS, and adopting an approach of using white papers, case studies, conference papers, peer review journal papers et cetera, the company can enhance its performance and results. This aligns to Fernie et al. (2003) and Wang and Wang, (2012).

\section{Marketing Approach Framework for Biomedical science SMES}

By gaining a greater understanding of the maturity of a product offer from a biomedical science SME, and aligning that to the appropriate marketing approach, an enhance marketing offer can be realised. When the respondent marketing approach is mapped against the relevant service TRL, the following was noted in the results (Figure 4 refers): 


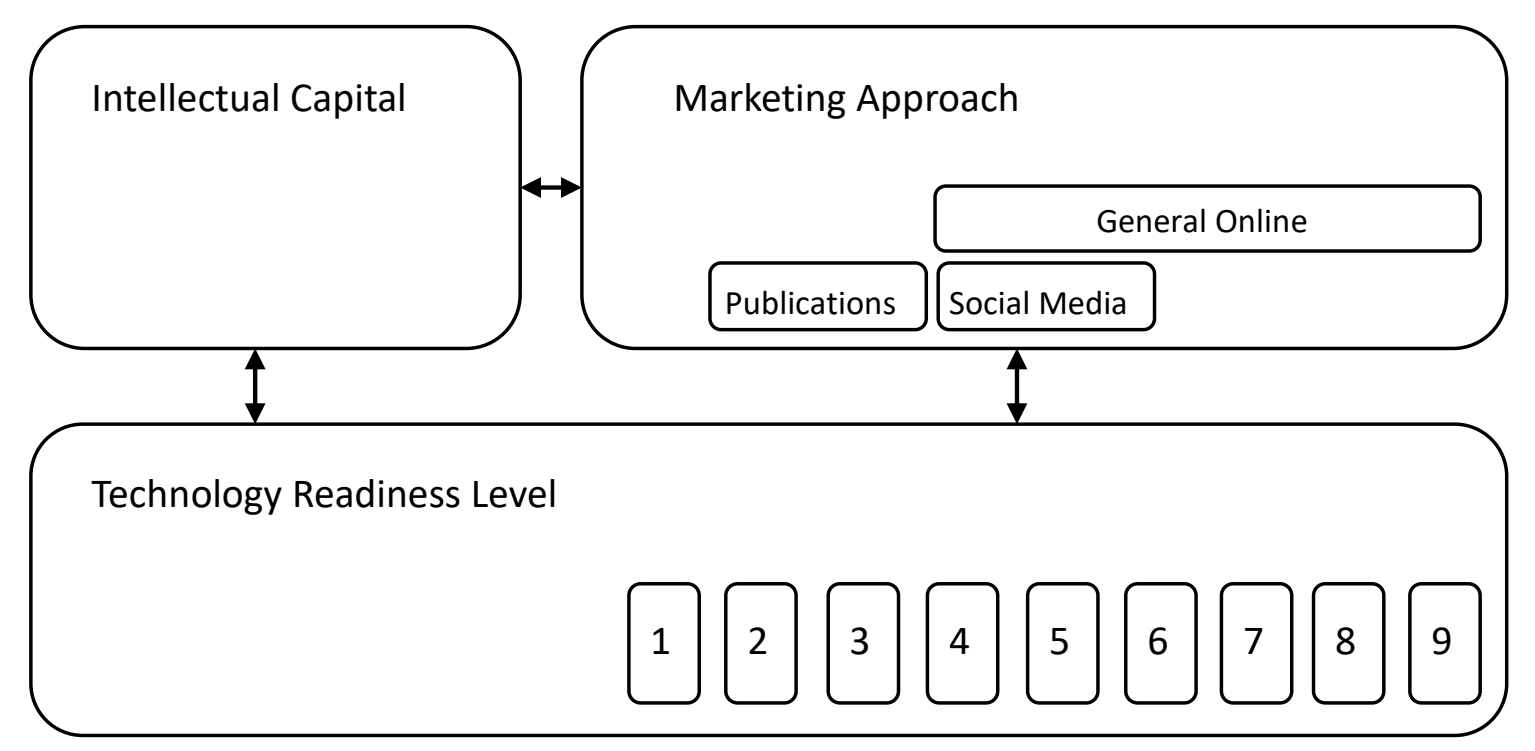

Figure 4. Refined Theoretical Framework (source: developed by author for the study)

By expanding this result and referencing the established literature, elements including KS and networking can be incorporated, validating the conceptual framework thus (Figure 5 refers):

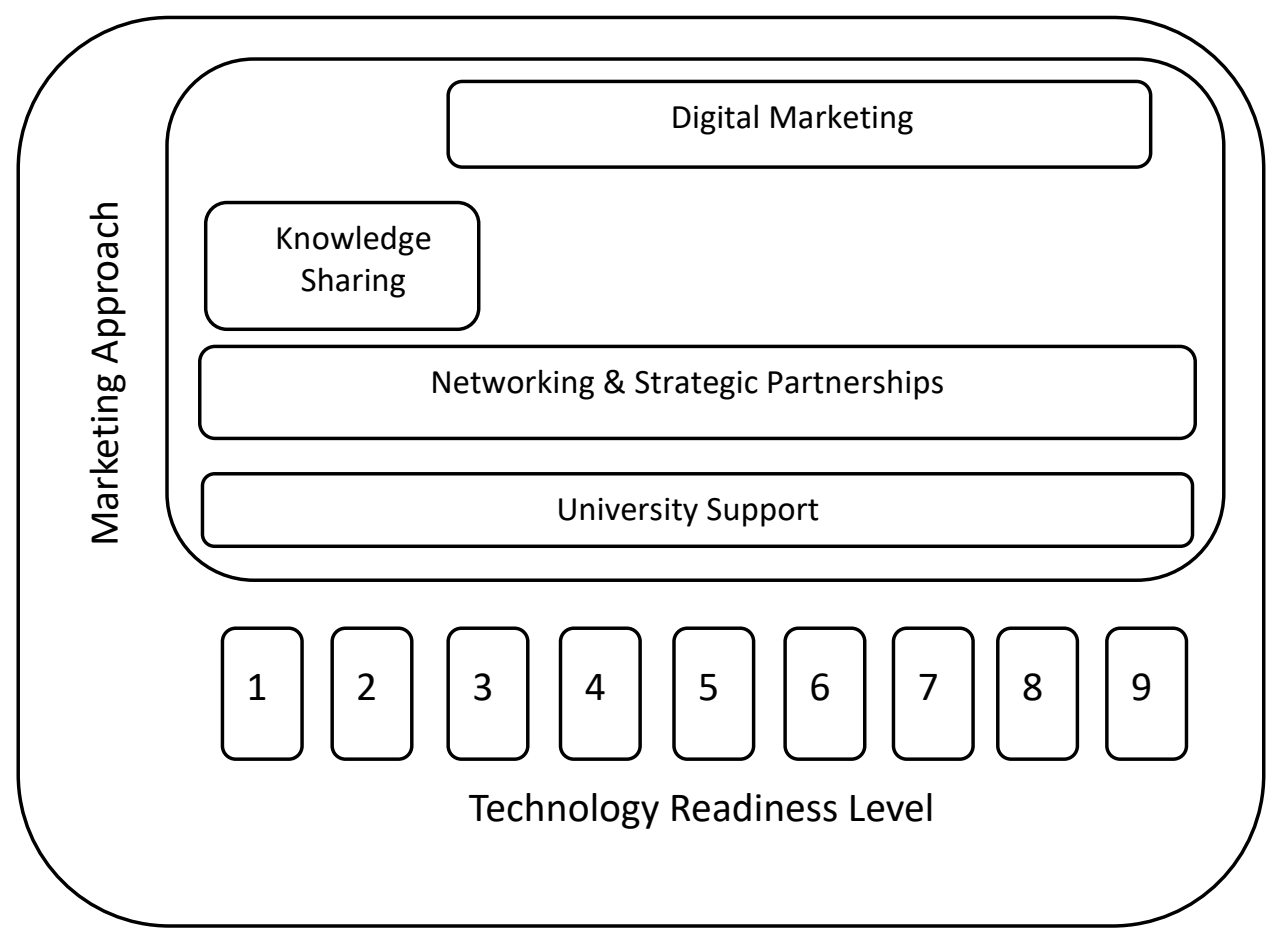

Figure 5. Marketing Approach Conceptual Framework for Biomedical science SMEs 
This study therefore presents a conceptual framework which highlights an established mechanism for identifying the maturity of a product using the TRL and aligns that to the appropriate marketing approach. The user identifies the maturity of the product using its TRL and aligns to the appropriate tactic. As the maturity of the service develops, so does the approach.

\section{Limitations of this research}

The study focused on Biomedical science SMEs and the actions taken in various stages of product development. Other factors that might have influenced these actions in biomedical science firms are not included in this study, for example leadership actions, in-depth research over government policies, study of sponsoring universities and their networking capabilities. Future research that includes these aspects may increase the knowledge of and insight of a marketing approach framework.

The study does not have specific explanation on what kind of support university is providing and why the support is limited to these companies and organisations. Hence, the study lacks in-depth research from the universities' point of view which underpins the understanding of future marketing actions. The study lacks additional information over in-depth issues of the companies' funding. The study did not cover the effects of the quality of collaborations, other internal resources such as management strategies, companies' organisational structures and cultures, and accumulated knowledge resources (Kang and Park, 2012).

\section{Conclusion}

A study was carried out to investigate the marketing tactics for biomedical science SMEs in the UK; the research question is: Should the marketing approaches for biomedical science SMEs change as their product or service moves along the development life cycle? An online questionnaire was used, and the results analysed. From the results of the study, this paper offers the contribution to literature by introducing a conceptual framework for determining the appropriate marketing approach for biomedical science SMEs; this is done by understanding the maturity of the products offered by a company in the development life cycle, and by using the related position of that product on the established TRL. The framework maps the TRL against known marketing tactics; this framework should be used as a guide for biomedical science SMEs as a tool to refine and evolve their overall marketing approach as the product portfolio matures along the development life cycle, and therefore the TRL. This conceptual framework is offered as a tool for decision makers and SME managers to guide their decision making with respect to marketing strategy as their product develops. 


\section{References}

Aliasghar, O., Sadeghi, A., \& Rose, E. L. (2020). Process innovation in small- and medium-sized enterprises: The critical roles of external knowledge sourcing and absorptive capacity. Journal of Small Business Management, 1-28. doi: 10.1080/00472778.2020.1844491

Bains, W., (2014). Funding biotech start-ups in a post-VC world. Journal of Commercial Biotechnology, Jan, 20(1), pp. 10-27.

Boni, A. A. (2018). Innovation Challenges and Opportunities in Biopharma, MedTech, Digital Medicine, and Their Emerging Convergence: User \& Patient Centric Applications in the "Pharma 3.0 Business Framework Paradigm." Journal of Commercial Biotechnology, 24(1).

Buganza, T., Colombo, G., \& Landoni, P. (2014). Small and medium enterprises' collaborations with universities for new product development. Journal of Small Business and Enterprise Development, 21(1), 69-86.

Chalmers, D. and Nicol, D. (2004) 'Commercialisation of biotechnology: public trust and research', International Journal of Biotechnology, 6(2/3), 116-133.

Costa, C., Fontes, M., \& Heitor, M. V. (2004). A Methodological Approach to the Marketing Process in the Biotechnology-based Companies. Industrial Marketing Management, 33(5), 403-418.

Cook, D. T. (2006). 40 In pursuit of the 'inside view': training the research gaze on advertising and market practitioners. Handbook of Qualitative Research Methods in Marketing. Edward Elgar Publishing Limited.

Douglas, S. P., \& Craig, C. S. (2006). On Improving the Conceptual Foundations of International Marketing Research. Journal of International Marketing, 14(1), 1-22.

Eriksson, P., \& Rajamäki, H. (2010). Biotechnology marketing: Insider and outsider views. Journal of Commercial Biotechnology, 16(2), 98-108.

Etzkowitz, H., \& Leydesdorff, L. (2000). The dynamics of innovation: from National Systems and "Mode 2" to a Triple Helix of university-industry-government relations. Research Policy, 29(2), 109123.

Fernie, S., Green, S. D., Weller, S. J., \& Newcombe, R. (2003). Knowledge sharing: context, confusion and controversy. International Journal of Project Management, 21(3), 177-187.

Festel, G., Detzel, C., \& Maas, and R. (2012). Industrial biotechnology-Markets and industry structure. Journal of Commercial Biotechnology, 18(1), 11-21.

Frau, M., Moi, L., \& Cabiddu, F. (2020). Outside-in, Inside-out, and Blended Marketing Strategy Approach: A Longitudinal Study. International Journal of Marketing Studies, 12(3), 1.

Fuster, E., Padilla-Meléndez, A., Lockett, N., \& del-Águila-Obra, A. R. (2018). The emerging role of university spin-off companies in developing regional entrepreneurial university ecosystems: The case of Andalusia. Technological Forecasting and Social Change, 141, 219-231.

Gleadle, P., Parris, S., Shipman, A., \& Simonetti, R. (2012). Financialisation As An Enabler Or Inhibitor Of Innovation? The Case Of UK Biotech. FINNOV. Milton Keynes 
Gunn, M. (2016). When science meets entrepreneurship: ensuring biobusiness graduate students understand the business of biotechnology. Journal of Entrepreneurship Education, 19 (2), 53-77.

Haug, A., Wickstrøm, K. A., Stentoft, J., \& Philipsen, K. (2020). The impact of information technology on product innovation in SMEs: The role of technological orientation. Journal of Small Business Management, 1-27. doi: 10.1080/00472778.2020.1793550

Howard, P., \& Doyle, D. (2006). An examination of buying centres in Irish biotechnology companies and its marketing implications. Journal of Business \& Industrial Marketing, Volume 21(Issue 5), 266280.

Ipe, M. (2003). Knowledge Sharing in Organizations: A Conceptual Framework. Human Resource Development Review, 2(4), 337-359.

Kang, K.-N. and Park, H. (2012) Influence of government R\&D support and inter-firm collaborations on innovation in Korean biotechnology SMEs, Technovation, 32(1), pp. 68-78.

Kolympiris, C., Kalaitzandonakes, N. and Miller, D. (2014) Public funds and local biotechnology firm creation, Research Policy, 43(1), pp. 121-137.

Kremer, H., Villamor, I. and Aguinis, H. (2019) Innovation leadership: Best-practice recommendations for promoting employee creativity, voice, and knowledge sharing, Business Horizons, 62(1), pp. 6574.

Lane, J. (2018). Expanded Technology Readiness Level (TRL) Definitions for the Bioeconomy. Biofuels Digest. Newstex.

Lee, Y., \& O'Connor, G. C. (2003). The Impact of Communication Strategy on Launching New Products: The Moderating Role of Product Innovativeness. Journal of Product Innovation Management, 20(1), 4-21.

Lindstrand, A., Melén, S., \& Nordman, E. R. (2011). Turning social capital into business: A study of the internationalization of biotech SMEs. International Business Review, 20(2), 194-212.

Liu, D., \& Zeinaly, S. (2020). A new framework for investigating the role of IT-based innovation in the pharmaceutical knowledge-sharing attitude: A study of marketing biotechnology firms. The international journal of cybernetics, systems and management sciences, (vol ahead of print)

Lokko, Y., Heijde, M., Schebesta, K., Scholtès, P., Montagu, M. V., \& Giacca, M. (2018). Biotechnology and the bioeconomy-Towards inclusive and sustainable industrial development. New Biotechnology, 40(Pt A), 5-10.

Malone, E. A., \& Wright, D. (2018). "To Promote That Demand": Toward a History of the Marketing White Paper as a Genre. Journal of Business and Technical Communication, 32(1), 113-147.

Mankins, J. C. (2009). Technology readiness assessments: A retrospective. Acta Astronautica, 65(910), 1216-1223.

Mu, J., Bao, Y. K., Sekhon, T., Qi, J. and Love, E. (2018) Outside-in marketing capability and firm performance, Industrial Marketing Management, 75, pp. 37-54 
Oakey, R. P. (2003). Funding innovation and growth in UK new technology-based firms: Some observations on contributions from the public and private sectors. Venture Capital, 5(2), 161-179.

Padilla-Meléndez, A., Fuster, E., Lockett, N., \& del-Aguila-Obra, A. R. (2020). Knowledge spillovers, knowledge filters and entrepreneurial university ecosystems. Emerging role of University-focused venture capital firms. Knowledge Management Research \& Practice, 1-12.

Pollock, T. G., Lee, P. M., Jin, K., \& Lashley, K. (2015). (Un) tangled: Exploring the asymmetric coevolution of new venture capital firms' reputation and status. Administrative Science Quarterly, 60(3), 482-517.

Polvinen, K., Patana, A.-S., Kanto, L., Pihlajamaa, J., \& Berg, P. (2012). Customer Understanding and Communication in New Technology and Research Services: An Empirical Study from Life Science Companies. Proceedings of PICMET '12: Technology Management for Emerging Technologies, 319326. IEEE.

Pronk, J. T., Lee, S. Y., Lievense, J., Pierce, J., Palsson, B., Uhlen, M., \& Nielsen, J. (2015). How to set up collaborations between academia and industrial biotech companies. Nature Biotechnology, 33(3), 237-240.

Rajamäki, H., (2008). Anticipating and managing the challenges of biotechnology marketing. Journal of Commercial Biotechnology, 06 May, Volume 14, 225-231.

Rampersad, G., Quester, P., \& Troshani, I. (2010). Managing innovation networks: Exploratory evidence from ICT, biotechnology and nanotechnology networks. Industrial marketing management, 39(5), 793-805.

Ranchhod, A., Gurãu, C., \& Hackney, R. (2000). Marketing on the Internet: observations within the biotechnology sector. International Journal of Physical Distribution \& Logistics Management, 30(7/8), 697-710.

Renko, M. (2006). Market Orientation in Markets for Technology - Evidence from Biotechnology Ventures. Publications of the Turku School of Economics Series. Esa Print Tampere

Saunders, M., Lewis, P., \& Thornhill, A. (2019). Research Methods for Business Students (8th ed.). England: Pearson Education.

Schlee, R. P., \& Duzer, J. B. V. (2015). An Examination of Alternative Approaches to the Treatment of Confidential Information in Live Case Projects. Marketing Education Review, 17(2), 71-82.

Thompson, P., Williams, R., \& Thomas, B. (2013). Are UK SMEs with active web sites more likely to achieve both innovation and growth? Journal of Small Business and Enterprise Development, 20(4), 934-965.

Varadarajan, R. (2010). Strategic marketing and marketing strategy: domain, definition, fundamental issues and foundational premises. Journal of the Academy of Marketing Science, 38(2), 119-140.

Wang, Y. S., \& Hsu, T. H. (2018). Dynamic capabilities of biologics firms in the emerging business market: Perspective of dynamic capabilities evident. Industrial Marketing Management, 71, 5-18. 
Wang, Z., \& Wang, N. (2012). Knowledge sharing, innovation and firm performance. Expert Systems with Applications, 39(10), 8899-8908.

Weitze, M. D., \& Pühler, A. (2013). Improving biotechnology communication. Biotechnology Journal, 8(9), 970-972.

Willerton, D. (2005). Ethos and exigence: White papers in high-tech industries. (Doctoral Dissertation).

Wang, Y.-S., \& Hsu, T.-H. (2018). Dynamic capabilities of biologics firms in the emerging business market: Perspective of dynamic capabilities evident. Industrial Marketing Management, 71, 5-18. 